\title{
VIVÊNCIAS DE EXCLUSÃO NA ACADEMIA: DESAFIOS À INTERCULTURALIDADE
}

\author{
Emília Coutinho ${ }^{1}$, Adriana Pinto Oliveira ${ }^{2}$, Carolina Marques Reis ${ }^{2}$, Inês Raquel Cabral \\ Oliveira ${ }^{2}$, Leonardo de Almeida Maltez ${ }^{2}$, Stefanie Marlene Pereira Osório ${ }^{2}$, Vitória Parreira ${ }^{3}$ \\ Paula Nelas ${ }^{1}$, Cláudia Chaves ${ }^{4}$, João Duarte ${ }^{1}$, Sandra Antunes ${ }^{4}$ e Paula Santos ${ }^{4}$ \\ ${ }^{1}$ Health Sciences Research Unit: Nursing (UICISA: E) | IPV, Polytechnic Institute of Viseu, Escola Superior de Saúde \\ Portugal.ecoutinhoessv@gmaill.com, pnelas@gmail.com, duarte.johnny@gmail.com \\ ²Enfermeiros portugueses, Portugal. adrianapintoo97@gmail.com, carolreispfm@gmail.com, innees96@gmail.com \\ maltez.leonardo@gmail.com, stefanieosorio.97@hotmail.com \\ ${ }^{3}$ Escola Superior de Enfermagem do Porto, Porto, Portugal. vitoria@esenf.pt \\ ${ }^{4}$ Politécnico de Viseu, Viseu, Portugal, claudiachaves21@gmail.com; sandramgantunes@gmail.com \\ psantos16@gmail.com
}

\begin{abstract}
Resumo. Introdução Relatos de vivências de exclusão académica apresentam-se como desafios às instituições de ensino superior (IES) na sua capacidade de desenvolverem, mas também de aplicarem políticas promotoras de interculturalidade; Objetivos Conhecer as práticas institucionais interpretadas como barreiras à inclusão e desafios à interculturalidade; e desocultar os sentimentos vividos pela comunidade académica em contextos experienciados que considerem de exclusão; Métodos Estudo qualitativo, fenomenológico-hermenêutico com recurso à entrevista fenomenológica a trinta membros da comunidade académica (estudantes, docentes e não docentes) de uma IES de Portugal, de abril a julho de 2019, com suporte a análise qualitativa de dados apoiada pelo Nvivo12. Este trabalho insere-se num projeto mais alargado intitulado "Práticas inclusivas no Ensino Superior: O desafio de construir comunidade", autorizado pela Comissão de Ética da Instituição envolvida; Resultados Apresentam-se as categorias "Barreiras à inclusão na instituição" e "Sentimentos vivenciados em experiências de exclusão". As barreiras à inclusão na instituição mais referenciadas foram barreiras arquitetónicas e desunião hierárquica na instituição. No que concerne aos sentimentos vivenciados em experiências de exclusão, os participantes referenciaram essencialmente o sentir-se desvalorizado, a solidão e a tristeza; Conclusões. As barreiras arquitetónicas da instituição, o sentir-se desvalorizado, a solidão e a tristeza são os principais desafios institucionais à inclusão e interculturalidade.
\end{abstract}

Palavras-chave: Sentimentos; Academia; Exclusão; Barreiras; Interculturalidade.

\section{EXCLUSION EXPERIENCES IN THE ACADEMY: CHALLENGES TO INTERCULTURALITY}

Abstract. Introduction Reports of academic exclusion experiences arise as challenges to higher education institutions (HEls) in their capacity to develop, but also to apply policies that promote interculturality; Objectives To know the institutional practices interpreted as barriers to inclusion and challenges to interculturality; and unveiling the feelings experienced by the academic community in experienced contexts that they consider to be exclusion; Methods Qualitative, phenomenologicalhermeneutic study using phenomenological interviews with thirty members of the academic community (students, teachers and non-teachers) from a Portuguese HEI, from April to July 2019 , supported by qualitative data analysis using Nvivo12. This work is part of a broader project entitled "Inclusive practices in Higher Education: The challenge of building a community", authorized by the Ethics Committee of the Institution involved; Results The categories "Barriers to inclusion in the institution" and "Feelings experienced in exclusion events" are presented. The most referenced barriers to inclusion were architectural barriers and hierarchical disunity in the institution. About the feelings experienced in exclusion events, the participants essentially referred to feeling devalued and loneliness; Conclusions. The architectural barriers of the institution and the feeling of being devalued, loneliness and sadness are the major institutional challenges to inclusion and interculturality.

Keywords: Feelings; Academy; Exclusion; Barriers; Interculturality. 


\section{INTRODUÇÃO}

De entre os tipos de exclusão económica, política e social como referido por Rodrigues (2020) muito se tem estudado sobre os impactos da exclusão social nomeadamente exclusão de género, cultural, étnica, patológica e religiosa (Cruz, 2018). A sociedade que não investe na educação, saúde, habitação, segurança e noutros requisitos sociais de vida digna, que não mitiga a pobreza, barbárie, racismo, xenofobia, iliteracia, e outras condições que comprometem a tomada de decisão livre e esclarecida, não é uma sociedade equitativa e íntegra, mas sim dividida, desordeira, intransigente, preconceituosa, injusta, fraturante, geradora de segregação, ignorância, insegurança, violência e exclusão (Dias Sobrinho, 2010). Para Alvino-Borba e Mata-Lima (2011), os principais fatores de exclusão social em Portugal e na Europa são o desemprego, o envelhecimento demográfico e a pobreza. Relatos de vivências de exclusão académica apresentam-se como desafios às instituições de ensino superior (IES) na sua capacidade de desenvolverem, mas também de aplicarem políticas promotoras de interculturalidade.

A inclusão em meio académico assenta na educação acessível a todos, quaisquer que sejam as especificidades. Rodrigues (2018) recorda que não é fácil promover o desenvolvimento de valores e práticas inclusivas, na academia, sendo uma missão complexa e polémica. Complexa porque na sua génese a escola não foi concebida para todos os estudantes, necessitando de várias correções em termos políticos, educacionais e de apoio a projetos de investigação focados na inclusão. Polémica porque apesar das recomendações internacionais em termos de Direitos Humanos, são as instituições de ensino que têm que reconhecer e atender às especificidades dos estudantes, adequando a sua missão e a sua estrutura em função de cada um. Em 1994 a UNESCO já defendia a inclusão académica, com programas curriculares ajustados (Tomelin, Paula, Sanchez, Peres \& Carvalho, 2018).

Numa política de qualidade e sucesso a longo prazo compete às IES promover e garantir a igualdade de oportunidades e a inclusão social, com corresponsabilização de toda a comunidade académica, assegurando direitos e deveres (Gregersen- Hermans, 2017).

O ensino superior é, ou deveria ser, por excelência um espaço privilegiado para a formação intercultural dos futuros profissionais; um cenário em que se aproximam conceções teóricas e estratégias práticas úteis e eficazes, para fomentar nos estudantes o desejo de conhecer e 
desenvolver a interculturalidade na sua futura prática profissional, num contexto de inclusão e cidadania (Leiva \& Bracons, 2019).

Os estudantes interagem num contexto controlado, com regras e normas, criando um ambiente análogo para todos, apesar de ser culturalmente diverso (Costa, 2019).

Num mundo cada vez mais global, as sociedades estão cada vez mais plurais decorrente do crescente fluxo de pessoas que atravessam as fronteiras internacionais. Dangis e Laoyan (2018) mostram que os estudantes com experiências multiculturais com os seus pares e mentores desenvolveram uma consciência cultural e construíram redes sociais. No entanto, referem também experiências negativas, como a discriminação, isolamento social e prática de segregação. Verificaram ainda que os principais fatores dificultadores de inclusão foram as barreiras linguísticas; que para se obterem benefícios da diversidade, é importante criar e promover um ambiente inclusivo; e que a interação cultural, estratégias de ensino autêntico, apoio das IES à diversidade e a competência cultural dos docentes são formas de promover a inclusão.

O desafio da educação inclusiva nas IES é alargado ao nível social, educacional e político. Importa a clarificação dos conceitos inclusão e integração, por vezes utilizados como sinónimos, mas que na sua essência são diferentes.

Entendemos que integrar significa formar, coordenar ou combinar, podendo resultar em perda de identidade, ao assumir a identidade da cultura dominante pela qual se foi assimilado, enquanto incluir significa compreender, fazer parte de ou participar em algo. Vemos o significado de inclusão aliado ao conceito de participação, uma necessidade primordial do ser humano. Assim, no contexto académico, o estudante do ensino superior só terá a possibilidade de total desenvolvimento quando incluído num todo, que permita a sua plena participação em todas as áreas da vida académica (Santos, Gonçalves, Ramos, Castro \& Lomeo, 2015).

A Declaração Mundial sobre o Ensino Superior atesta que este deve ser acessível a todos, enquanto direito humano fundamental, pilar da democracia, do desenvolvimento sustentável e da paz (Santos et al., 2015). Se por um lado, as IES são o centro do conhecimento, por outro, devem ser o centro da pluralidade, da diversidade e do respeito à diferença (Moreira, Bolsanello, \& Seger, 2011). 
Neste contexto surgem duas questões de investigação. Quais as práticas institucionais interpretadas como barreiras à inclusão e desafios à interculturalidade? Que sentimentos são vividos pela comunidade académica em contextos experienciados que considerem de exclusão?

\section{METODOLOGIA}

Estudo qualitativo, fenomenológico-interpretativo, centrado na experiência vivida na academia pelos participantes.

A metodologia qualitativa procura compreender os fenómenos e apresentá-los nos seus variados sentidos (Oliveira, Barros \& Souza, 2017). Spradley (1980) realça esses sentidos na linguagem nativa e na interpretação do investigador. Existe uma estreita relação entre o investigador e o participante pelo que é fundamental compreender a intencionalidade e o significado, compreender os credos, ideias, perceções, representações, perspetivas, conexões, que os participantes atribuem às próprias ações, em interação com os outros e com o ambiente (Amado, 2014). Em investigação qualitativa a análise dos dados inicia aquando do início da recolha de dados.

Considerámos a visão de Van Manen (2015) sobre a fenomenologia, enquanto uma maneira particular de olhar e se posicionar perante a experiência vivida dos participantes. Método focado na forma de perguntar, no questionamento que nos possibilita o acesso à compreensão da forma como experienciamos o mundo (Van Manen, 2007). Esta perspetiva de Van Manen, conduz sem impor, no qual não há uma rigidez do método, mas sim o iluminar do percurso possibilitando que o investigador faça o seu próprio caminho (Pereira (2015). Van Manen (2014) foca-se no modo como se desenvolve a ação e interação de cada participante enquanto ser no mundo. Heidegger realça o valor formativo da escrita fenomenológica para a reflexão entre o ser e o agir, quem somos e como nós atuamos, contrariamente ao que se possa pensar que seria para criar normas, técnicas, procedimentos, ou modelos prescritivos do que fazer ou da forma como fazer (Van Manen, 2007)

O questionamento filosófico em contextos clínicos permite compreender o que as pessoas vivem e sentem na interação cliente-prestador de cuidados. São esses sentidos cognitivos e não cognitivos, a perceção da existência, como refere Van Manen, que nos ajudam a entender o significado que é atribuído a um determinado fenómeno pelas pessoas alvo dos 
cuidados de enfermagem (Pereira, 2015). Para tal importa que o investigador faça um corte epistemológico e se torne um ignorante consciente para poder captar a experiência vivida como ela é entendida pelos participantes. O investigador é um observador do mundo procurando o sentido que os participantes atribuem a cada fenómeno vivido. Neste sentido a pesquisa fenomenológica tem mais a ver com uma atitude de se posicionar no mundo, do que propriamente com um conjunto de passos a seguir (Van Manen, 2014).

Importou aqui, captar a experiência humana tal como foi vivida, mais do que a mera descrição dos factos. O foco de atenção em fenomenologia é a experiência vivida por determinada pessoa, e não a pessoa especificamente que descreve essa experiência, ou o contexto em que se encontra; a fenomenologia não se foca nos factos, mas na experiência humana (Van Manen, 2014).

A comunidade académica foi previamente informada da realização do estudo pelos presidentes das unidades orgânicas envolvidas. O presente estudo obedeceu aos critérios éticos das pesquisas com seres humanos, pelo que todo o processo de investigação se iniciou após a explicação, sobre o propósito e os procedimentos, a gravação das entrevistas e a cessação da sua participação a qualquer momento, obtendo o seu consentimento informado livre e esclarecido para a participação no estudo. Previamente o projeto de investigação foi submetido e aprovado pela Comissão de Ética da instituição envolvida.

Foram 30 os participantes no estudo, 10 docentes, 10 não docentes e 10 estudantes (Figura 1).

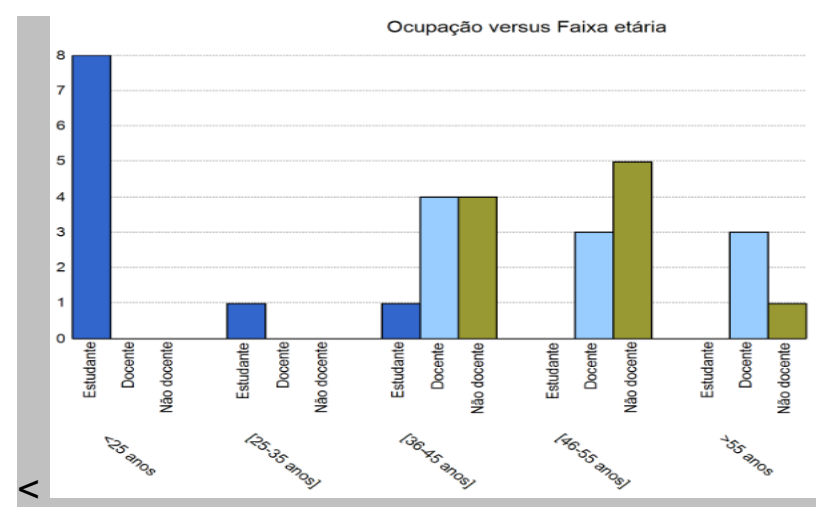

Figura 1. Distribuição dos participantes em função da ocupação e faixa etária

Foram incluídas quatro áreas científicas de cinco unidades orgânicas de uma IES de Portugal (Figura 2) 


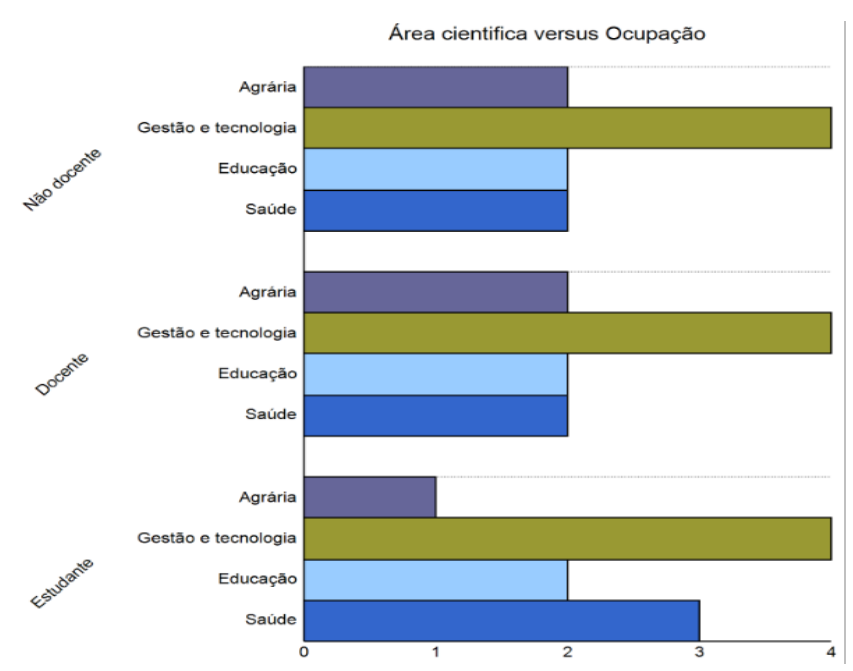

Figura 2. Distribuição dos participantes em função da área cientifica e ocupação

Dos critérios definidos para a seleção dos participantes foi considerada a experiência e facilidade em comunicar.

Quanto à nacionalidade, $90 \%$ são portugueses e $10 \%$ estrangeiros, nomeadamente de Alemanha, Angola e Brasil.

Entre as várias alternativas metodológicas de colheita de dados, optou-se pela entrevista fenomenológica com as questões gerais: Fale-me de contextos institucionais experienciados por si que considera terem dificultado a sua inclusão e interculturalidade? O que sentiu nesses contextos experienciados?

Tendo em vista dar resposta às questões de investigação formuladas, cada participante expressou as suas perceções de acontecimentos e situações vivenciadas bem como as suas interpretações e o sentido que Ihes atribuía. Sentimos que os participantes estiveram à vontade, falaram livremente das suas experiências e valorizaram o facto de haver a preocupação em recolher o seu sentir a nível desta problemática. As entrevistas decorreram de abril a julho de 2019, num gabinete reservado para o efeito e tiveram a duração média de 45 minutos, no entanto, com dois dos participantes docentes, houve necessidade da realização de dois encontros.

Durante a análise seguimos os pressupostos de Van Manen $(2007,2014,2015)$ para compreender a experiência vivida: em primeiro lugar foi necessário voltarmo-nos para a natureza da experiência vivida, a qual passou por selecionar o fenómeno, a perspetiva de 
estudo, o contexto onde decorreu, e os participantes; seguidamente investigámos a experiência vivida, que prevê entrar no contexto de estudo, obter as descrições experienciadas, e sair do contexto do estudo; em terceiro lugar desenvolvemos uma reflexão fenomenológica hermenêutica; em quarto lugar elaborámos uma escrita fenomenológica hermenêutica; em quinto lugar mantivemos uma relação orientada para o fenómeno; em sexto lugar contrabalançámos o contexto da pesquisa (Van Manen, 2014, 2015). Suportámos a organização dos dados no $\mathrm{Nvivo}^{\circledR}$ versão12. Este software permitiu organizar, classificar, ordenar, examinar relações e combinar análises, cruzando dados emergentes da análise com dados de caracterização dos participantes, entre outras. Neste estudo centrámo-nos na análise do verbatim das entrevistas e destes dados foi possível criar diversas categorias e subcategorias. Pela natureza e tamanho deste artigo apenas foi possível apresentar duas categorias e respetivas subcategorias de análise, nomeadamente "Barreiras à inclusão na instituição" e "Sentimentos vivenciados em experiências de exclusão" as quais estão em total coerência com as questões de investigação formuladas. As categorias foram validadas pelos seis primeiros investigadores apresentados neste artigo, primeiramente em processo isolado e posteriormente em grupo tendo-se procedido aos ajustamentos necessários em função do entendimento do todo.

Contribuição dos autores: os primeiros seis autores do presente artigo trabalharam na conceção, execução, análise, interpretação e construção do artigo; os restantes contribuíram na construção do artigo.

\section{RESULTADOS E DISCUSSÃO}

Apresentam-se duas categorias emergentes "Barreiras à inclusão na instituição" e "Sentimentos vivenciados em experiências de exclusão" nas tabelas 1 e 2, em que n corresponde ao número de participantes e $\mathrm{F}$ ao número de unidades de registo.

\subsection{Barreiras à inclusão na instituição}

A categoria "Barreiras à inclusão na instituição" é constituída por dez subcategorias. As mais destacadas foram "Barreiras Arquitetónicas", com dez unidades de registo e "Desunião hierárquica na instituição" com quatro unidades de registo.

A menos referida pelos entrevistados foi o "Acolhimento ser realizado pela praxe" com uma unidade de registo", como apresentado na Tabela 1. 
Tabela 1. Barreiras à inclusão na instituição

\begin{tabular}{lcc}
\hline Barreiras à inclusão na instituição & $\mathrm{n}$ & $\mathrm{F}$ \\
\hline Barreiras arquitetónicas & 8 & 10 \\
Desunião hierárquica na instituição & 1 & 4 \\
Dificuldade linguística & 3 & 3 \\
Turmas e grupo de amigos restrito & 2 & 3 \\
Falta de capacidade financeira & 2 & 3 \\
Falta de recursos institucionais & 3 & 3 \\
Crenças e valores & 1 & 2 \\
Desrespeito pelos lugares reservados a pessoas com necessidades & 1 & 2 \\
específicas & 1 & 2 \\
Estabelecimento de pré-requisitos & 1 & 1 \\
Acolhimento ser realizado pela praxe & 1 \\
\hline
\end{tabular}

Apresentam-se alguns dos testemunhos dos participantes reflexivos de cada uma das subcategorias:

\section{- Barreiras arquitetónicas}

"Temos um estudante que é deficiente motor, em cadeira de rodas e temos algumas dificuldades... até em salas que estão com uma ocupação demasiado elevada, às vezes é difícil movimentar-se" (ED2).

"Temos edifícios afastados uns dos outros e em alguns locais, há barreiras físicas, como escadas, rampas, caminhos que são em terra, com buracos, às vezes com lama, há essa dificuldade" (ED2).

"barreiras físicas por se tratar de um edifício que já tem muitos anos ...com vicissitudes" (ED8).

"casas de banho, as portas são difíceis de abrir, para nós é difícil, imagine para pessoas que têm mais dificuldade" (EE2).

\section{- Desunião hierárquica na instituição}

"Proximidade [entre as unidades orgânicas] não está ainda contemplada na instituição" (ED4).

"Sendo só de cima, emanado de cima, torna-se difícil, que cada um conheça aquilo que se passa na instituição" (ED4). 


\section{- Dificuldade linguística}

"linguagem... porque a maior parte deste tipo de programas [Erasmus] necessita da língua inglesa... há muita dificuldade e a instituição não nos dá ferramentas para ultrapassar esta barreira" (EE9).

"a principal barreira é a língua... há pouca gente a falar inglês. E isso é um problema. Quer estudantes, quer professores, quer funcionários, colaboradores" (EN5).

\section{- Turmas e grupo de amigos restrito}

"[As pessoas] criam os seus próprios grupos e só falam com aquele grupo" (EE4).

"Eu sei que é mais fácil o facto de haver duas turmas, mas desta forma, nós não conseguimos incluir tanto a turma $B$, portanto acho que isso é uma barreia" (EE7).

\section{- Falta de capacidade financeira}

"A não atribuição de bolsas a alunos que se calhar precisam" (EE10).

"Perder a bolsa por falta de créditos" (EE10).

"Há disciplinas e cursos que os alunos têm de fazer trabalhos. Há muito mais facilidade para quem tem dinheiro para comprar o material para aplicar e fazer os projetos, e aqueles que não têm, não é tão fácil. Depois os professores vão avaliar pelo que esta feito e não pelo esforço que tiveram para o fazer. É chato quando estamos no ensino público, que se defende tanto, e depois voltamos ao mesmo, consoante as possibilidades, assim se dá a nota" (EN7).

\section{- Falta de recursos institucionais}

"Era importante que a instituição apostasse não só na contratação de professores de língua gestual como também na utilização de equipamentos para invisuais e para pessoas com surdez para acederem a materiais de apoio e acompanhamento das aulas" (ED10).

"Por vezes, no ensino não superior há... até a nível de acompanhamento mais personalizado [pessoas com necessidades específicas], o que por vezes não acontece no ensino superior" (ED6). 


\section{- Crenças e valores}

"Algumas crenças que podem existir [constituem-se barreiras à inclusão na instituição]" (ED10).

"Pessoas que têm determinados valores que muitas vezes são difíceis de mudar, tal como perspetivas também que têm [constituem-se barreiras à inclusão na instituição]" (ED3).

- Desrespeito pelos lugares reservados a pessoas com necessidades específicas

"Estacionarem nos lugares dos deficientes indevidamente" (EN2).

"Noto que ainda há pessoas que descriminam essas pessoas [com necessidades específicas] apesar de haver legislação acerca disso" (EN2).

\section{- Estabelecimento de pré-requisitos}

"Nós temos uma licenciatura em que adotámos os pré-requisitos e foi algo que foi muito discutido, e por vezes apercebemo-nos que há determinado tipo de formações em que se torna muito mais difícil incluir ou poder incluir todos... porque implica práticas em que há pessoas com alguns tipos de deficiência que ficam impossibilitadas de as realizar" (ED2).

"Penso que deve haver oportunidades de igual forma, mas às vezes tem que haver alguma adaptação por parte das pessoas... em algumas áreas de formação torna-se mais difícil, especificamente para quem tem determinado tipo de deficiência... concordo com inclusão, sim, mas por outro lado penso que há situações em que não é possível, ou torna muito mais difícil de conseguir essa inclusão" (ED2).

\section{- Acolhimento ser realizado pela praxe}

"O acolhimento na instituição ser feito pelos praxantes da mesma” (EE5).

Relativamente às "Barreiras à inclusão na instituição", esta categoria é constituída por dez subcategorias, sendo as mais destacadas as "Barreiras Arquitetónicas" e "Desunião hierárquica na instituição". As barreiras arquitetónicas, segundo Rodrigues (2018), nos espaços escolares devem ser anuladas, uma vez que a acessibilidade ao meio físico é fundamental para a inclusão dos estudantes com mobilidade condicionada. Como defendem Ciantelli e Leite (2016, p. 413), a inclusão de pessoas com deficiência no ensino superior 
deve ser uma realidade premente, o que pressupõe a anulação de todas as barreiras, incluindo as arquitetónicas.

\subsection{Sentimentos vivenciados em experiências de exclusão}

A categoria "Sentimentos vivenciados em experiências de exclusão" é constituída por oito subcategorias. A subcategoria mais referenciada foi "Sentir-se desvalorizado" com cinco unidades de registo e as menos referidas foram as subcategorias "Desamparo", "Sentir dificuldade em relacionar-se" e "Desmotivação" com uma unidade de registo cada, conforme apresentado na Tabela 2.

Tabela 2. Sentimentos vivenciados em experiências de exclusão

\begin{tabular}{lcc}
\hline Sentimentos vivenciados em experiências de exclusão & $\mathrm{n}$ & $\mathrm{F}$ \\
\hline Sentir-se desvalorizado & 3 & 5 \\
Solidão & 3 & 3 \\
Tristeza & 3 & 3 \\
Mal-estar & 2 & 3 \\
Sentir-se incapaz & 2 & 2 \\
Desamparo & 1 & 1 \\
Sentir dificuldade em relacionar-se & 1 & 1 \\
Desmotivação & 1 & 1 \\
\hline
\end{tabular}

Apresentam-se algumas unidades de registo que dão corpo às três subcategorias mais referenciadas pelos participantes:

\section{- Sentir-se desvalorizado}

"Sinto-me uma carta fora do baralho" (EN3).

"[O não ser incluída] deixa-me desinserida do meio" (ED3).

"Eu sinto-me muitas vezes desenquadrada, porque realmente são vidas diferentes [pela diferença de idades]" (EE11).

\section{- Solidão}

"[O não ser incluído] é uma sensação muito estranha, uma sensação de estarmos sozinhos quando estamos rodeados de muita gente" (ED3).

"Senti-me um bocado sozinho [por não me adaptar à cidade]" (ED8).

"afasto-me e refugio-me no silêncio... quando não tenho bem para falar, é melhor calar-me" (EN3).

\section{- Mal-estar}

"Não me senti bem [com a praxe], pelo que me afastei dessa atividade" (EE5). 
"E isso dói muito, principalmente porque são comunidades católicas que estão a excluir" (EN3).

\section{- Tristeza}

"O não ser incluído... é algo que para a minha personalidade me deixa triste" (ED3).

"[Senti-me] triste com o que se estava a passar comigo [não me adaptar à cidade]" (EE8).

"É triste [não ser incluída]" (EN3).

\section{- Sentir-se incapaz}

"Eu por vezes sinto que podia ter sido mais esclarecedor e ter ajudado mais [na comunicação com colega estrangeiro]" (EE6).

"Sinto que mesmo com o passar do ano ainda há pessoas que estão um pouco de parte e por mais que eu tente ajudar, acabo por não ter muito sucesso" (E402).

\section{- Desamparo}

"Mais uma vez para referenciar, senti-me desamparado, pelo facto de ter ido procurar alojamento, sem ter ninguém a quem recorrer na altura" (E196).

Sentir dificuldade em relacionar-se.

"Sabemos nós [docentes] que é difícil fazer amigos no nosso local de trabalho [na instituição]" (ED7).

\section{- Desmotivação}

"[O não me incluírem] não me motiva minimamente para eu continuar dentro do trabalho que estou a desenvolver" (ED3).

Constatou-se ainda que, no que se refere à categoria "Sentimentos vivenciados em experiências de exclusão", constituída por oito subcategorias, a mais referenciada foi "Sentir-se desvalorizado". A este respeito reforça-se o pressuposto de que os estudantes do ensino superior só terão a possibilidade de total desenvolvimento quando incluídos no contexto escolar num todo, permitindo-Ihe a sua pela participação em todas as áreas da vida académica (Santos et al., 2015, p. 252), o que implica a adoção de estratégias que levem os estudantes a terem experiências positivas e não de desvalorização, seja a que nível for. Também Dangis e Laoyan (2018) mostram no seu estudo que os estudantes vivenciaram experiências negativas sentindo discriminação, isolamento social e prática da segregação, e 
que as barreiras linguísticas dificultaram a inclusão; recomendando que para promover a inclusão é importante criar e promover um ambiente inclusivo, em que haja respeito na interação racial, se desenvolvam estratégias de ensino de apoio à diversidade e que a competência cultural dos docentes seja uma realidade. Autores como Poker, Valentim e Garla (2018) referem no seu estudo que os próprios docentes reconhecem as suas falhas e a escassa formação na área da inclusão, com implicações na formação e capacitação da comunidade académica no geral a este nível.

\section{CONCLUSÕES}

O presente estudo de investigação qualitativa permitiu desocultar os sentimentos vividos pela comunidade académica em contextos experienciados que os participantes consideraram de exclusão, e permitiu igualmente conhecer as práticas institucionais interpretadas como barreiras à inclusão e desafios à interculturalidade; tendo emergido como principais barreiras à inclusão na instituição as barreiras arquitetónicas e desunião hierárquica. Quanto aos sentimentos vivenciados em experiências de exclusão os mais apontados foram o sentir-se desvalorizado, a solidão e a tristeza. Estes resultados darão à IES o conhecimento que a capacite para desenvolver estratégias e políticas institucionais promotoras de práticas de inclusão e interculturalidade, servindo também como um ponto de partida a uma futura monotorização levando ao desenvolvimento de novas investigações e novas práticas institucionais. Sendo as IES espaços de produção e partilha de conhecimento por excelência, mas também os locais onde se podem encontrar as pessoas com maior formação académica de um país, estes resultados permitirão que as IES reflitam na sua missão, nas suas práticas, na essência da sua natureza e na definição e implementação de políticas institucionais que lhes permitam construir uma comunidade na diversidade e pluralidade.

Agradecimentos. UICISA-E; Politécnico de Viseu/Missão para a Inclusão /Centro Local de Apoio à Integração de Migrantes/SPECULA; Alto Comissariado para as Migrações/Rede de Ensino Superior em Mediação Intercultural/Programa Mentores para Migrantes; SIGMA Tetha Tau- Phi Xi Chapter. Trabalho financiado pela Fundação para a Ciência e a Tecnologia, I.P., no âmbito do projeto Ref ${ }^{a}$ UIDB/00742/2020. 


\section{REFERÊNCIAS}

Alvino-Borba, A., \& Mata-Lima, H. (2011). Exclusão e inclusão social nas sociedades modernas: um olhar sobre a situação em Portugal e na União Europeia. Serv. Soc. Soc., São Paulo(106), 219-240.

Amado, J. (Coord). (2014). Manual de investigação qualitativa em educação. Coimbra: Imprensa da Universidade de Coimbra.

Ciantelli, A.P.C., \& Leite, L.P. (2016). Ações Exercidas pelos Núcleos de Acessibilidade nas Universidades Federais Brasileiras. Rev. Bras. Ed. Esp., Marília, v. 22, 3, 413-428

Costa, D. (2019). Diversidade Cultural na Universidade em Portugal: Tendências e Desafios. In: Gonçalves, S., \& Costa, J.J. (Coord.). Diversidade no Ensino Superior (pp. 11-36). Coimbra: Coleção Estratégias de Ensino e Sucesso Académico: Boas Práticas no Ensino Superior. Em https://www.cinep.ipc.pt/attachments/article/186/\%20Diversidade\%20no\%20ensino\%20superior\%202019\%20v23\%20ONLINE+.pdf

Cruz, N. (2018). Exclusão Social. Em https://querobolsa.com.br/enem/sociologia/exclusao-social

Dangis, G. H., e Laoyan, M. (2018). The Influence of Multiculturalism within Higher Education: Nursing. (Degree Programme in Nursing Bachelor of Health Care), Arcada University of Applied Sciences, Helsinque.

Dias Sobrinho, J. (2010). Democratização, qualidade e crise da educação superior: faces da exclusão e limites da inclusão. Educação \& Sociedade, 31, 1223-1245. Em http://www.scielo.br/scielo.php?script=sci_arttext\&pid=S0101-73302010000400010\&nrm=iso

Glenda Helen Dangis, Meriam Laoyan 2018 ver pdf https://www.theseus.fi/handle/10024/147763

Gregersen-Hermans, J. (2017). Intercultural Competence Development in Higher Education. Em https://www.researchgate.net/publication/313388295_Intercultural_Competence_Dev elopment_in_Higher_Education/download

Leiva, J. \& Bracons, H. (2019). La educación intercultural en la formación inicial del profesorado: la voz de los docentes universitarios. In A. M. Costa e Silva, I. Macedo \& S. Cunha (Eds.), Livro de atas do II Congresso Internacional de Mediação Social: a Europa como espaço de diálogo intercultural e de mediação (pp. 2845). Braga: CECS.

Moreira, L., Bolsanello, M., e Seger, R. (2011). Ingresso e permanência na Universidade: alunos com deficiências em foco. Educar em Revista, 0.

Oliveira, E.S.F de, Barros, N.F. de, \& Souza, D.C.D.B.N de (2017). Metodologias qualitativas em diferentes cenários: saúde e educação. Goiânia: Gráfica UFG.

Pereira, P. S. (2015). Fenomenologia da prática: investigação em enfermagem da experiência vivida. Rev enferm UFPE on line Recife, 9(10), 9608-9615. doi:10.5205/reuol.7944-69460-1-SM.0910201525

Poker, R. B., Valentim, F. O. D., \& Garla, I. A. (2018). Inclusão no ensino superior: a percepção de docentes de uma instituição pública do interior do estado de São Paulo. Psicologia Escolar e Educacional, 22, 127-134. Em http://www.scielo.br/scielo.php?script=sci_arttext\&pid=S1413-85572018000400127\&nrm=iso

Rodrigues, D. (2018). Aprofundar a inclusão com o que se sabe. Jornal O Publico 18 de Abril de 2018, 6:48. Acesso em, 2020, em https://www.publico.pt/2018/04/18/sociedade/opiniao/aprofundar-a-inclusao-com-oque-se-sabe-1810760

Rodrigues, L. O. (2020). Exclusão social. Em https://alunosonline.uol.com.br/sociologia/exclusao-social.html

Santos, E., Gonçalves, M., Ramos, I., Castro, L., \& Lomeo, R. (2015). Inclusão no Ensino Superior: Perceções dos estudantes com Necessidades Educativas Especiais sobre o ingresso à universidade. Revista Portuguesa de Educação, 28(2), 251-270. 
Spradley, J. (1980). Participant Observation. New York: Holt Rinehart and Winston.

Tomelin, K.N., Dias, A.P.L., Sanchez, M., Peres, J., \& Carvalho, S. (2018). Educação inclusiva no ensino superior: desafios e experiências de um núcleo de apoio discente e docentes. Rev. Psicopedagogia; 35(106), 94-103.

Van Manen, M. (2007). Phenomenology of Practice. Phenomenology \& Practice, 1(1), 11 - 30.

Van Manen, M. (2014). Phenomenology of Practice: Meaning Giving Methods in Phenomenological Research and Writing. Walnut Creek, California: Left Coast Press.

Van Manen, M. (2017). But is it phenomenology?. Qualitative Health Research, 27(6), 775-779. doi:10.1177/1049732317699570 